DOI: $10.17805 / z p u .2015 .4 .21$

\title{
Формирование потребностных ожиданий родительской общественности средствами педагогической диагностики
}

\author{
Л. В. РОМАНЮК \\ (МОСКОВСКИЙ ГУМАНИТАРНЫЙ УНИВЕРСИТЕТ), \\ Г. Н. СКУДАРёВА
}

(ГОСУДАРСТВЕННЫЙ ГУМАНИТАРНО-ТЕХНОЛОГИЧЕСКИЙ УНИВЕРСИТЕТ, Г. ОРЕХОВО-ЗУЕВО)

Прогнозирование перспективных направлений развития образования невозможно вне социально-экономического контекста и без учета интересов и потребностей полноправного социального субъекта образования - родителей обучающихся, или синонимичной педагогической категории - родительской общественности. Новая социальная роль родителей диктует потребность дифференциации их социально-педагогических функций, расширения спектра участия в функционировании, развитии и управлении образованием, об усложнении его содержания. Трансформация взаимоотношений школы и родителей отражена в приоритетах современной образовательной политики. С целью успешного проектирования их взаимодействия необходимо диагностировать потребностные ожидания родителей от школы с целью информирования о том, как ответственно школа относится к поручениям государства и реагирует на запросы общества в лице родительской общественности. Существенным дополнением к полученным выводам могут служить обобщенные результаты современных исследований, свидетельствующие о наиболее общих характеристиках потребностных ожиданий родителей от школы.

Ключевые слова: образовательные отношения; родительская общественность; школа; семья; общественный запрос; социальные потребности; педагогическая диагностика

\section{ВВЕАЕНИЕ}

\оренные преобразования, происходящие в российском обществе, привнесли серьезные изменения в систему образования. Образовательные учреждения, включившись в инновационные процессы, активно ведут поиск новых форм работы по разным направлениям своей деятельности. По-новому школа начинает выстраивать свои отношения с семьей - бесспорной общечеловеческой ценностью, транслирующей культурное наследие, этнические нормы и традиции. Их значение в современных условиях возрастает не только для каждой отдельной личности, но и для общества в целом. Традиционно семье принадлежит основная роль в формировании социальных идеалов ребенка, в семье закладываются основы его гражданского поведения, указываются границы идентификации, а также семья является первым и самым глубоким источником формирования защитного «стиля жизни» как средства социально-психологической адаптации.

Аанное положение особенно актуально в условиях введения и реализации ФГОС (Федерального государственного образовательного стандарта) нового поколения. «Образовательный стандарт - инструмент исполнения Конституции Российской Федерации. ФГОС - ориентация на будущее. Руководствоваться при образовательных реформах запросами и реалиями сегодняшнего дня - значит остановиться в развитии. Мы должны закладывать в стандарты образования модель будущего», - считает А. М. Кондаков (Кондаков: Электронный ресурс).

\section{СЕМЬЯ КАК ФАКТОР СРЕАЫ ВОСПИТАНИЯ}

Новый ФГОС, определяя семью как важнейший институт общества, основу и опору государства, отвечающую за социализацию новых поколений, рассматривает роди- 
телей как равноправных участников образовательных отношений. «В целях обеспечения реализации основной образовательной программы начального общего образования в образовательном учреждении для участников образовательного процесса должны создаваться условия, обеспечивающие возможность участия обучающихся, их родителей (законных представителей), педагогических работников и общественности в разработке основной образовательной программы начального общего образования, проектировании и развитии внутришкольной социальной среды, а также в формировании и реализации индивидуальных образовательных маршрутов обучающихся» (Федеральный государственный ... , 2009: Электронный ресурс).

Это означает, что залогом легитимности стандарта является адекватный учет потребностей всех субъектов образовательного процесса. По мнению А. $\Lambda$. Константиновского, В. С. Вахштайна, А. Ю. Куракина, именно учет реальных ориентаций субъектов образования (кто, кому и с какой целью адресует свой «социальный запрос») подтверждает новый статус стандарта как «общественного договора», акцентируя внимание на полноправии участников или субъектов образовательных отношений в лице родителей обучающихся (Константиновский и др., 2013: 68).

Семья совместно со школой создает тот важнейший комплекс факторов воспитывающей среды, который определяет успешность либо неуспешность всего учебно-воспитательного процесса. Современная семья развивается в условиях качественно новой противоречивой общественной ситуации. С одной стороны, наблюдается поворот общества к проблемам семьи, разрабатываются и реализуются комплексные целевые программы по укреплению и повышению ее значимости в воспитании детей. С другой стороны, наблюдаются процессы, которые приводят к обострению семейных проблем. Это прежде всего падение жизненного уровня большинства семей, решение проблем әкономического, а порой и физического выживания, что усилило социальную тенденцию самоустранения многих родителей от решения вопросов воспитания и личностного развития ребенка. Все вышесказанное весьма актуализирует проблему взаимодействия семьи и школы в условиях реализации ФГОС нового поколения и обозначает необходимость выявления потребностных ожиданий родительской общественности от школы в новом контексте (Скударёва, 2014).

\section{АИАГНОСТИКА ОЖИААНИЯ РОАИТЕАЕЙ ОТ ШКОАЫ}

С целью обеспечения объективности выводов представляется целесообразным диагностировать потребностные ожидания родителей от школы как полноправных участников образовательных отношений, ввиду того что перечень задач, возложенных государством на образовательные учреждения, достаточно широк, и очень важно знать, как оценивают их выполнение родители учащихся, насколько ответственно школа подходит к поручениям государства и реагирует на запросы общества в лице родительской общественности. Аиагностические исследования проведены на базе муниципальной средней общеобразовательной школы с использованием следующих методик: авторской методики Т.Ф. Фоминой, О. К. Самарцевой, М. И. Горшковой, О. Н. Руссовой «Как узнать, что думают родители о школе, или Методические рекомендации по изучению мнения родителей о работе школы» (Как узнать ... , 2009); рекомендаций по оценке общественностью образовательного учреждения Т. А. Фоминой (Фомина, 2008); методики изучения удовлетворенности родителей работой образовательного учреждения, разработанной Е. Н. Степановым. 
В качестве диагностического инструментария использованы методы анкетирования и опроса. Количество диагностируемых составило 60 человек, из которых 30 учащихся в возрасте 13-15 лет, 30 человек - родители этих же детей. Анализ данных опроса показал, что относительно высоко родители оценили реализацию школой образовательной, воспитательной и социализирующей задач (функций). Аанная оценка согласуется с позицией родителей относительно репутационных характеристик образовательного профиля: 77,4\% опрошенных родителей считают, что школа осуществляет хорошую базовую подготовку по всем предметам. Несколько ниже оценена родителями работа школы по решению таких задач, как «присмотр» за ребенком в течение дня, помощь родителям в воспитании ребенка, создание психологического комфорта для ребенка. Важно понять контекст данных оценок. Какие «сигналы» посылают родители о ребенке, обращая внимание на «присмотр» за ним, важность «психологического комфорта» и просьбы о помощи в воспитании?

Относительно высоко оценена работа школы по решению следующих задач: помощи ребенку к подготовке в профессиональные учебные заведения, в выборе профессии, создании условий для развития талантов ребенка. Высокие оценки по последней характеристике даны в связи с наличием следующих ресурсов в школе: спортивных секций, кружков, участники которых успешно выступают в различных городских соревнованиях, получая всевозможные награды. Широко развита система мероприятий, направленных на выявление и проявление детьми творческих способностей, организация концертов, выставок, фестивалей.

Организацию безопасного пребывания ребенка в школе родители оценивают в целом положительно: 69,7\% опрошенных устраивают эти условия. Эмоциональная атмосфера в школе, по оценке родителей, в целом благоприятная: 70,1\% респондентов считают ее хорошей. Очевидна некоторая неустойчивость в оценках родителей исследуемых характеристик. Кроме того, данные опроса демонстрируют противоречивость позиции родителей по отношению к школе. С одной стороны, декларируется потребность в консультировании и помощи в воспитании детей - выполнение этой задачи школой устраивает $60 \%$ родителей, остальные $40 \%$ явно или неявно нуждаются в помощи. Усилия школы по привлечению родителей к организации ее жизни положительно оценивают $64,5 \%$ опрошенных.

С другой стороны, только 14,1\% опрошенных родителей сообщили о желании влиять на жизнь школы, а 30,2\% обозначили лишь некую слабую готовность к сотрудничеству. Регулярные личные встречи с учителями также не являются распространенной практикой среди опрошенных родителей в школе, об этом виде контактов сообщили 29,4\% опрошенных. Можно сказать, что родители дистанцированы от школы, но вместе с тем родители желают, чтобы дети были всесторонне охвачены вниманием, эмоциональным теплом. Не случайно показатель «реализация индивидуального подхода к обучающемуся» составил только 45,1\%: опрошенные согласились, что владеют навыками его осуществления. Как видно, те усилия, которые создает школа, не всегда находят отклик у родителей в силу различных обстоятельств. Приведенные данные проблематизируют политику взаимодействия с родителями:

- во-первых, в родительской среде растет понимание необходимости переориентации образовательной системы с модели «человек знающий»на модель «человек социальный», а также на модель «человек - творческая индивидуальность»;

- во-вторых, декларируется потребность прозрачности системы требований к учащимся при переходе от одной образовательной ступени к другой (дошкольное обра- 
зовательное учреждение - школа, школа - профессиональное образование) и адекватности этим требованиям собственно подготовки учащихся;

- в-третьих, усиливается запрос родителей на предоставление возможностей обсуждения с общественностью «обязательного» содержания образовательных программ и вариативной его составляющей (Фомина, 2008: 17).

На уровне конкретной школы родители формулируют требования по принципу «от противного», т. е. образовательный процесс должен быть организован таким образом, чтобы решить назревшие в настоящий момент проблемы. В этом смысле существует родительский запрос на формирование содержания образовательных программ либо по принципу соответствия их требованиям, формулируемым в учреждениях профессионального образования, либо по принципу «жизненной необходимости» в будущем.

\section{ПОТРЕБНОСТИ РОАИТЕАЕЙ}

Распространение компетентностной модели образования как приоритета ФГОС, принципов здоровьесбережения в процессе обучения приводит к тому, что у родителей формируются потребности в иной организации образовательного пространства для своих детей. Прежняя организация процесса обучения, по их мнению, не способна дать предполагаемый в этой связи результат.

Рассматривая школу с точки зрения отношений к ней жителей близлежащей территории, участники исследования обратили внимание на потребность в сохранении безопасности сосуществования. Ответственность за обеспечение условий, защищающих детей от неадекватного поведения подростков микрорайона, респонденты возлагают на администрацию школы.

В силу того что в родительской среде пока не осознана сама потребность оценивать деятельность школы как института, оказывающего образовательные услуги населению, отсутствует не только комплексный, но и дискретный перечень критериев оценки образовательного учреждения родителями. Образовательные учреждения если и сравниваются родителями между собой, то пока только по обобщенному критерию «качество образования» и сложившемуся на этом основании имиджу учреждения. В этой ситуации технология и процедура оценки образовательного учреждения остаются для родительской общественности в целом неясными. Отдельные же родители, получившие опыт работы в общественных органах управления образовательным учреждением, остро ощутили необходимость в дополнительной подготовке и обучении технологиям работы. Результаты изучения удовлетворенности родителей жизнедеятельностью образовательного учреждения показали, что высокий уровень удовлетворенности опрошенных родителей преобладает над низким. Только 5\% респондентов на утверждения: «...мы испытываем чувство взаимопонимания в контактах с администрацией и учителями нашего ребенка», «...учебное заведение способствует формированию достойного поведения нашего ребенка» - отмечали несоответствие данных высказываний реалиям. Практически полностью удовлетворены взаимодействием школьного коллектива и семейным социумом $70 \%$ родителей. У остальных анкетируемых уровень удовлетворенности работой образовательного учреждения и его педагогического коллектива отмечен как средний $-24 \%$.

Представляется, что существенным дополнением к полученным выводам могут служить обобщенные результаты современных исследований, свидетельствующие о наиболее общих характеристиках потребностных ожиданий родителей от школы. 
Вместе с тем, отмечая достаточно определенные требования к школе, выступающие основанием для принятия «потребительского» выбора, Т. Ф. Фомина, О. К. Самарцева, М. И. Горшкова, О. Н. Руссова указывают на пока еще слабую выраженность сформированного запроса родительской общественности к системе образования. Исследователи отмечают некоторую разобщенность в потребностных ожиданиях родителей, отсутствие определенного вектора в их направленности. И. В. Селиверстова и С. Г. Косарецкий, например, констатируют, что основные направления общественной компоненты общественного запроса проецируют создание здоровьесберегающих условий осуществления образовательного процесса, обеспеченность материальнотехнической базы, наличие высококвалифицированных педагогов, высокие шансы на вертикальную мобильность в результате обучения в средней школе (Косарецкий, Селиверстова, 2009: Электронный ресурс).

\section{ЗАКАЮЧЕНИЕ}

Таким образом, в результатах исследования представлены различные аспекты школьной деятельности, и характерен тот факт, что по преимущественному большинству из этих аспектов у родителей сформировано собственное мнение, сформулированы потребностные ожидания, удовлетворение которых может существенно влиять на организацию и содержание образовательного процесса в соответствии с требованиями ФГОС в то время, когда всем уже стало очевидно, что родительское сообщество составляет ядро «общественности», которое непосредственно вовлечено в процессы функционирования, развития и управления школой. Несмотря на то что первые шаги по формированию активной общественной позиции родителей сделаны, эта социально-педагогическая функция родителями еще не до конца осознана и, следовательно, не реализована. Задача школы в этой связи - обеспечить эффективное взаимодействие с родительской общественностью, придав инновационность данному процессу в подходах, организации, содержании, формах и методах.

\section{СПИСОК АИТЕРАТУРЫ}

Как узнать, что думают родители о школе, или Методические рекомендации по изучению мнения родителей о работе школы (2009) / Т. Ф. Фомина, О. К. Самарцева, М. И. Горшкова, О. Н. Руссова. Архангельск ; Самара : Центр «Социальная механика» ; Центр социальных измерений «Фокус». 36 с.

Кондаков, А. М. Реализация ФГОС общего образования в условиях новой образовательной среды [Электронный ресурс]// Государственное бюджетное образовательное учреждение дополнительного педагогического профессионального образования Центр повышения квалификации специалистов Красносельского района Санкт-Петербурга. Информационно-методический центр. URL: http://imc.edu.ru/files/fgos/Презентации\%20по\%20ФГОС/Реализация\% 20ФГОС\%20Кондаков.pdf [архивировано в WebCite] (дата обращения: 16.05.2014).

Константиновский, А. $\Lambda$, Вахштайн, В. С., Куракин, А. Ю. (2013) Реальность образования. Социологическое исследование: от метафоры к интерпретации : учеб. пособие для социологических факультетов университетов. М. : Центр социального прогнозирования и маркетинга. $224 \mathrm{c}$.

Косарецкий, С. Г., Селиверстова, И. В. (2009) Родители и школа: что мешает диалогу? [Электронный ресурс] // Первое сентября. №6. URL: http://ps.1september.ru/article.php?ID= 200900612 [архивировано в WebCite] (дата обращения: 12.09.2015).

Скударёва, Г. Н. (2014) Современные родители как субъекты формирования социального заказа и эксперты качества образования // Семейное воспитание в отечественном образовании. Орехово-Зуево : Изд. центр Моск. гос. областного гуманит. ин-та. 150 с. С. 98-113. 
Федеральный государственный общеобразовательный стандарт начального общего образования (1-4 кл.) (2009) [Электронный ресурс]// Министерство образования и науки Российской Федерации. 6 октября. URL: http:// минобрнауки.рф/документы/922 [архивировано в archive.is] (дата обращения: 12.09.2015).

Фомина, Т. А. (2008) Оценка образовательного учреждения общественностью: потребности и критерии. Самара : Центр «Социальная Механика»; АНО «Ааборатория модернизации образовательных ресурсов». 35 с.

Аата поступления: 13.10 .2015 2.

SHAPING NEEDS-RELATED EXPECTATIONS IN PARENTS' COMMUNITIES

BY MEANS OF PEDAGOGICAL DIAGNOSTICS

L. V. ROMANIUK

(MOSCOW UNIVERSITY FOR THE HUMANITIES),

G. N. SKUDARYOVA

(State UnIVERSITY For ENGINEERING AND tHe Humanities, OreKHovo-ZueVo)

Predicting which directions in the development of education will prove most promising is impossible without accounting for both the socio-economic context and the interests and needs of a fullfledged social subject of education - students' parents ('the community of parents' can be accepted as a synonym). The new social role that parents play calls for variegating their socio-pedagogical functions, for expanding the range of participation in the educational performance, development and management, as well as for making its content more complex. The priorities of current educational policy correspond to the transformation of the relationship between the school and parents. For their interaction to succeed, it is necessary to first determine the needs-related expectations parents' communities have. The school should inform them how responsibly the school treats the instructions from the state authorities and responds to the needs of society as personified by the parents' community. The summary of the outcomes of contemporary research, listing the most general features of the needs-related expectations parents' communities have from the school, might prove an important additions to the findings obtained.

Keywords: educational relations; parent community; school; family; public demand; social needs; pedagogical diagnostics

\section{REFERENCES}

Kak uznat', chto dumaiut roditeli o shkole, ili Metodicheskie rekomendatsii po izucheniiu mneniia roditelei o rabote sbkoly [How to find out what parents think of their children's school, or Methodological guidelines for studying parents' opinion on the school's performance] (2009) / T. F. Fomina, O. K. Samartseva, M. I. Gorshkova and O. N. Russova. Arkhangelsk ; Samara, Tsentr «Sotsial'naia mekhanika» Publ. ; Tsentr sotsial'nykh izmerenii «Fokus» Publ. 36 p. (In Russ.).

Kondakov, A. M. Realizatsiia FGOS obshchego obrazovaniia v usloviiakh novoi obrazovatel'noi sredy [Implementing the Federal Standards of General Education under the conditions of the new educational environment]. Gosudarstvennoe biudzhetnoe obrazovatel'noe uchrezhdenie dopolnitel' nogo pedagogicheskogo professional' nogo obrazovaniia Tsentr povysheniia kvalifikatsii spetsialistov Krasnosel'skogo raiona Sankt-Peterburga. Informatsionno-metodicheskii tsentr [online] Available at: http://imc.edu.ru/files/fgos/Презентации\%20по\%20ФГОС/Реализация\%20ФГОС\% 20Кондаков.pdf [archived in WebCite] (accessed 16.05.2014). (In Russ.).

Konstantinovskii, D. L, Vakhshtain, V. S. and Kurakin, D. Yu. (2013) Real' nost' obrazovaniia. Sotsiologicheskoe issledovanie: ot metafory $k$ interpretatsii [The reality of education. A sociological survey: From metaphor to interpretation]: A textbook for higher school sociology majors. Moscow, Tsentr sotsial'nogo prognozirovaniia i marketinga Publ. 224 p. (In Russ.).

Kosaretskii, S. G. and Seliverstova, I. V. (2009) Roditeli i shkola: chto meshaet dialogu? [Parents and the school: What hinders the dialogue?]. Pervoe sentiabria, no. 6. [online] Available at: 
http://ps.1september.ru/article.php?ID=200900612 [archived in WebCite] (accessed 12.09.2015). (In Russ.).

Skudaryova, G. N. (2014) Sovremennye roditeli kak sub»ekty formirovaniia sotsial'nogo zakaza i eksperty kachestva obrazovaniia [Parents in contemporary Russia as subjects of the social mandate and experts in education quality]. In: Semeinoe vospitanie $v$ otechestvennom obrazovanii [Personal development in the family in Russian education]. Orekhovo-Zuyevo, Moscow State Regional Institute for the Humanities Publ. Center. 150 p. Pp. 98-113. (In Russ.).

Federal'nyi gosudarstvennyi obshcheobrazovatel'nyi standart nachal'nogo obshchego obrazovaniia (1-4 kl.) [Federal Standard of Primary General Education (grades 1-4)]. (2009) Ministerstvo obrazovaniia $i$ nauki Rossiiskoi Federatsii [Ministry of Education and Science of the Russian Federation], October 6. [online] Available at: http:// минобрнауки.рф/документы/922 [archived in archive.is] (accessed 12.09.2015). (In Russ.).

Fomina, T. A. (2008) Otsenka obrazovatel' nogo uchrezbdeniia obshchestvennost' iu: potrebnosti $i$ kriterii [The assessment of an educational institution by the public: needs and criteria]. Samara, Tsentr «Sotsial'naia Mekhanika» Publ. ; ANO «Laboratoriia modernizatsii obrazovatel'nykh resursov» Publ. 35 p. (In Russ.).

Submission date: 13.10 .2015$.

Романюк Аариса Валерьевна - доктор педагогических наук, проректор по научной работе, профессор кафедры педагогики и психологии высшей школы Московского гуманитарного университета. Адрес: 111395, Россия, г. Москва, ул. Юности, А. 5. Тел.: +7 (499) 374-58-81. Эл. адpec:lora1408@mail.ru

Скударёва Галина Николаевна - кандидат педагогических наук, доцент, заведующая кафедрой педагогики Государственного гуманитарно-технологического университета. Адрес: 142611, Россия, Московская область, г. Орехово-Зуево, ул. Зеленая, д. 22. Тел.: +7 (496) 425-65-65. Эл. aapec: fdp@mgogi.ru

Romaniuk Larisa Valerievna, Doctor of Pedagogy, Vice Rector for Research, Professor, Department of Pedagogy and Psychology of Higher School, Moscow University for the Humanities. Postal address: 5 Yunosti St., 111395 Moscow, Russian Federation. Tel.: +7 (499) 374-58-81. E-mail: lora1408@mail.ru

Skudaryova Galina Nikolayevna, Candidate of Psychology, Associate Professor and Chair, Department of Pedagogy, State University for Engineering and the Humanities. Postal address: 22 Zelyonaya St., 142611 Orekhovo-Zuyevo, Moscow Oblast, Russian Federation. E-mail: fdp@mgogi.ru 